\title{
Hypothesis: Causes of Type 2 Diabetes in Progeroid Werner Syndrome
}

\author{
Lynne S. Cox* \\ Department of Biochemistry, University of Oxford, South Parks Road, Oxford, OX1 3QU, UK
}

\begin{abstract}
The premature ageing Werner syndrome (WS) is characterized by the early onset of many age related phenotypes, including graying of hair, cataracts, atherosclerosis, cancer and type 2 diabetes. Type 2 diabetes (DM2) is the loss of blood glucose homeostastis, due to insulin resistance and a failure of acute glucose-stimulated insulin secretion (GSIS) by pancreatic $\beta$ cells. Early compensation for insulin resistance usually occurs through increased insulin secretion consequent on increased $\beta$ cell mass, requiring proliferation of $\beta$ cells; DM2 progresses if there is failure of compensation. How loss of the WRN DNA helicase/exonuclease in WS contributes to DM2 has long been a puzzle. Loss of function mutations in WRN result in problems with DNA replication, repair and recombination, consequential genomic instability and premature onset of cellular senescence. Here, I suggest that the high prevalence of DM2 in WS is a consequence of senescence of WS $\beta$ cells, with islet cells undergoing highly premature failure of the hyperproliferative compensatory stage, rapidly leading to late stage diabetes. The additional contribution to DM2 progression by pro-inflammatory cytokines is discussed.
\end{abstract}

\section{WERNER SYNDROME}

Loss of the WRN helicase/exonuclease results in the premature ageing Werner's syndrome, recapitulating many of the features of normal ageing [1]. Whilst WS patients usually display short stature, failure of the pubertal growth spurt, very low body mass index and loss of subcutaneous body fat, they also suffer from altered triglyceride metabolism and significant abdominal fat deposition, together with a very high incidence of atherosclerosis and arteriosclerosis [2]. In addition, patients show insulin resistance, accompanied by low levels of adiponectin and high circulating levels of plasma TNF- $\alpha[3,4]$; type 2 diabetes mellitus (DM2) is a highly penetrant phenotype [2]. Thus the majority of Werner syndrome patients develop clinically important DM2, and associated acceleration of atherosclerosis.

How does the loss of a single protein, WRN, lead to altered lipid and glucose metabolism and a strong predisposition to develop type 2 diabetes? In vitro, the WRN protein has been characterized as a 3'-5' helicase of the RecQ family [5] and it also possesses a 3'-5' exonuclease activity within an $\mathrm{N}$ terminal domain unique amongst the RecQ family [6]. Cultured human WS fibroblasts and lymphoblastoid cells show very premature onset of replicative senescence, with some WS patient fibroblast lines undergoing senescence after only $\sim 20$ population doublings, compared with the 5060 of normal fibroblasts [7]. This premature senescence is associated with significant defects in DNA repair and recombination, and particularly a problem with replication fork progression over unusual DNA structures [8-10] caused either by endogenous template elements such as fragile $\mathrm{X}$ sites $[11,12]$ or by exogenous DNA damage (reviewed in [13]). The resulting DNA instability appears to trigger a stress pathway mediated through p38 MAP kinase, together with

*Address correspondence to this author at the Department of Biochemistry, University of Oxford, South Parks Road, Oxford, OX1 3QU, UK;

E-mail: lynne.cox@bioch.ox.ac.uk expression of genes such as $\mathrm{p} 16^{\mathrm{INK} 4 / 6}$ and $\mathrm{p} 21^{\mathrm{CDKN} 1}$ that trigger and maintain the senescent state (reviewed in [14]). Inhibiting the stress signaling pathway through use of inhibitors of p38 kinase (MAPK, also known as stress-associated protein kinase, p38 SAPK) such as SB203580 restores an essentially normal cell morphology and proliferation kinetics to Werner's syndrome fibroblasts [15], emphasizing the importance of stress and DNA damage signaling in the pathology of WS. Because of the rarity of the disease, the senescent phenotype of many other WS cell types is unknown, though it is likely that many rapidly proliferating cell types will, like fibroblasts and lymphoblastoid cells, progress rapidly to senescence.

\section{STAGES IN DEVELOPMENT OF TYPE 2 DIABETES}

Type 2 diabetes (DM2), also known as non-insulin dependent diabetes (NIDD) usually occurs gradually over the course of years, with insulin resistance preceding development of the full clinical disease. Five stages have been proposed in disease progression (reviewed in [16]). In response to insulin resistance and mild glycaemia, a compensatory stage 1 occurs with increased insulin production arising predominantly as a consequence of increased $\beta$ cell mass via proliferation (also known as $\beta$ cell replication), neogenesis and hypertrophy of $\beta$ cells. Stage 2 represents a stable adaptation phase in which true glucose regulation is not fully maintained and where changes to $\beta$ cell activity and phenotype occur, including significant shifts in gene expression leading to dedifferentiation and loss of acute glucosestimulated insulin secretion (GSIS). Stage 3 is generally called a decompensation phase, with the suggestion that $\beta$ cell mass becomes inadequate, although a recent systems modeling approach suggests that this so-called decompensation stage actually represents a phase when the system is still trying to compensate for ongoing functional and cellular loss (Armin Rashid, pers. comm.) by hyperproliferation of pancreatic islet cells to provide more insulin; failure of this hyperproliferative stage leads to true hypoproliferative decom- 
pensation stage 4 . Although in autoimmune type 1 diabetes, this can rapidly progress to stage 5 with ketosis, stage 4 is usually stable in DM2. Loss of up to half of the $\beta$ cell mass has been observed post mortem in patients with DM2 [17] and rodent studies show major dedifferentiation [18]. Although increased apoptosis of $\beta$ cells is often assumed to account for loss of cell mass, inadequate $\beta$ cell replication or neogenesis with normal rates of apoptosis could equally contribute to a decrease in cell mass, since this is normally maintained through fine balance between cell birth (proliferation and neogenesis) and cell death (apoptosis and, to a lesser extent, necrosis) [16]. Indeed, enhanced apoptosis was not observed in partially pancreatomized rats in stage 4 diabetes [19].

To compensate for a decrease in $\beta$ cell number or diminished cell function (e.g. on dedifferentiation of pre-existing $\beta$ cells), there is a requirement for rapid $\beta$ cell proliferation. However, when cultured in vitro, $\beta$ cells proliferate poorly, reaching a state of replicative senescence within only 10-15 population doublings, with increased SA- $\beta$ gal staining, shortened telomeres and increased expression of $\mathrm{p} 16^{\mathrm{INK} 4 / 6}$ [20], all hallmarks of senescence. Interestingly, ectopic expression of hTERT, while restoring telomerase activity in the $\beta$ cells, did not rescue them from senescence [20]. Normal $\beta$ cells therefore undergo rapid senescence in vitro, and it is likely that a similar process occurs in vivo [21]. If the cells are additionally lacking WRN helicase/exonuclease and thus even more prone to senesce early, as in WS, it is highly likely that there will be a premature inability to compensate, with rapid progression to the more clinically severe later decompensation stages of diabetes. This could account for the high incidence of DM2 in WS patients.

\section{DRIVERS OF SENESCENCE IN WS $\boldsymbol{\beta}$ CELLS}

The altered lipid and glucose metabolism observed in DM2 may in part be consequent on peroxisome proliferatoractivated receptor (PPAR) dysregulation [22-24], and further exacerbated by inflammation and oxidative damage. Indeed, a role for inflammatory cytokines, particularly interleukin-6, has been demonstrated in the pathogenesis of DM2 in WS [25]. Recently, IL-6, among other inflammatory cytokines, has been shown to relay signals for oncogene-induced senescence [26, 27]. Moreover, WS patients show high levels of circulating inflammatory cytokines such as TNF- $\alpha$ [3]. Inflammation contributing to tissue ageing is highly likely [28], and such inflammation leads to formation of reactive oxygen species at high local concentrations [29]. Interestingly, WS cells are hypersensitive to oxidative damage not simply at the level of DNA repair [30]. Oxidative damage may drive senescence through telomere shortening [31], and it has been observed that white blood cells from diabetic patients with microalbuminuria (indicative of oxidative damage to the kidney) have shorter telomeres than those from diabetic patients without oxidative kidney damage [32]. However, is unlikely that such telomere shortening contributes significantly to $\beta$ cell senescence, since, as noted above, hTERT expression does not extend the proliferative capacity of $\beta$ cells in vitro [20]. A discussion of senescence of other cells such as endothelial progenitor cells, whilst probably important in the overall pathogenesis of DM2, is beyond the scope of this paper.
A combination of accumulated DNA damage, inflammation and oxidative stress resulting from altered metabolism, and high levels of stress signaling are probable drivers of cellular senescence (reviewed in [1, 14]). The greatly accelerated onset of cellular senescence in Werner's syndrome associated with early loss of proliferative capacity therefore means that the early response to insulin resistance i.e. hyperproliferation of islet cells, is therefore likely to be limited. Interestingly, mice mutant for the cyclin dependent kinase Cdk4 show normal early development of the pancreas, but islet function requires $\mathrm{Cdk} 4$, with null mice showing insulin resistance [33]. This is entirely consistent with a requirement for proliferation in the development and function of the pancreas: human WS patients show stunted overall growth, as do the Cdk4 mice, and perhaps they share also incomplete growth and inadequate functioning of the pancreas due to a deficit in cell proliferation caused, in the case of WS, by premature cell senescence. Similarly, cyclin D2 null mice show a post-natal deficit in pancreatic $\beta$ cell replication and associated (mild) diabetes [34]. Developmental deficits in the pancreas cannot therefore be ruled out at this stage as a significant factor in subsequent diabetes in WS.

Given the imbalance of lipid metabolism in WS patients (as modeled in mice mutant for the helicase domain of WRN - [35]), type 2 diabetes is an inherent risk. Mice null for WRN fed on a diabetogenic diet do indeed succumb to diabetes very readily [36], showing fatty change in the liver and pancreatic hyperproliferation. What is not yet clear is whether such mice show a rapid failure of the hyperproliferative phase due to the early onset of senescence, as predicted here. There is some conflict in the literature as to the impact of various naturally occurring polymorphisms of WRN in terms of DM2 predisposition; in a Japanese study, the Cys1367Arg polymorphism protects against diabetes [37], whilst in Chinese patients it has been reported that the same polymorphism is associated with early onset of diabetes [38]. Whatever the impact of the polymorphism (and it may be genuinely different in different genetic backgrounds), it is clear that loss of WRN function strongly predisposes to the development of insulin resistance and type 2 diabetes.

\section{TREATING DIABETES IN WS}

Various complications associated with insulin resistance including dyslipidemia and visceral fat deposition are likely to contribute to the high risk of cardiovascular disease in WS $[1,2]$. Treating WS patients with the PPAR $\gamma$ agonist pioglitazone, which regulates transcription of insulin-sensitive genes (including MAP kinases, glucose-6-phosphatase, pyruvate dehydrogenase and $\mathrm{NAD}(\mathrm{P}) \mathrm{H}$ dehydrogenase, to name only a few - [39]) leads to beneficial changes in fat distribution and serum adiponectin levels, together with a decrease in insulin resistance [3, 4, 40, 41]. Stress kinase signalling through the p38 MAP kinase pathway is elevated in diabetes (and also induced in response to high glucose concentrations - [42]). Given the remarkable impact of MAP kinase inhibitor SB203580 in restoring a normal proliferative phenotype to WS fibroblasts [15], it is certainly worth testing in vivo-tolerated analogues such as BIRB 796 [43] in murine models of WS to determine whether they positively impact on pancreatic function through restoration of islet cell proliferation. In this context, it is worth noting that BIRB 796 treatment of humans leads to a significant reduction in TNF- 
$\alpha$ [44], a key inflammatory cytokine that probably contributes to DM2 pathogenesis in WS [3, 25]. Thus p38 MAPK inhibition might result both in enhanced $\beta$ cell proliferation and a decrease in the inflammatory load on the pancreas which would otherwise drive senescence. However, as a note of caution, is possible that upregulation of p38 MAPK may be important in preventing islet $\beta$ cell apoptosis [45], and as such, its inhibition may lead to loss of the very cells that are required to prevent development of DM2.

\section{ACKNOWLEDGEMENTS}

I thank Dr Penelope Mason for helpful comments on the manuscript. This work was supported by the Biotechnology and Biological Sciences Research Council [grant numbers BB/E000924/1 and BB/E016995/1].

\section{ABBREVIATIONS}

Cdk4 $=$ cyclin dependent kinase 4
DM2 diabetes mellitus type 2
GSIS $=$ glucose stimulated insulin secretion
IL6 $=$ interleukin 6
MAPK $=$ mitogen activated protein kinase
PPAR $=$ peroxisome proliferator-activated receptor
SAPK $=$ stress associated protein kinase
TNFo $=$ tumour necrosis factor alpha
WRN $=$ Werner syndrome helicase/exonuclease
WS $=$ Werner syndrome

\section{REFERENCES}

[1] Cox LS, Faragher RG. From old organisms to new molecules: integrative biology and therapeutic targets in accelerated human ageing. Cell Mol Life Sci 2007; 64: 2620-41.

[2] Goto M, Miller RW. From Premature Gray Hair to HelicaseWerner Syndrome: Implications for Aging and Cancer. Gann Monograph on Cancer Research No. 49. Japan Scientific Societies Press, Tokyo, 2001; pp. 178.

[3] Yokote K, Hara K, Mori S, Kadowaki T, Saito Y, Goto M. Dysadipocytokinemia in werner syndrome and its recovery by treatment with pioglitazone. Diabetes Care 2004; 27: 2562-3.

[4] Hashimoto N, Hatanaka S, Yokote K, et al. A patient with Werner syndrome and adiponectin gene mutation. Diabetes Res Clin Pract 2007; 75: 27-9.

[5] Gray MD, Shen JC, Kamath-Loeb AS, et al. The Werner syndrome protein is a DNA helicase. Nat Genet 1997; 17: 100-3.

[6] Huang S, Li B, Gray MD, Oshima J, Mian IS, Campisi J. The premature ageing syndrome protein, WRN, is a $3^{\prime}-->5^{\prime}$ exonuclease. Nat Genet 1998; 20: 114-6.

[7] Faragher RG, Kill IR, Hunter JA, Pope FM, Tannock C, Shall S. The gene responsible for Werner syndrome may be a cell division "counting" gene. Proc Natl Acad Sci USA 1993; 90: 12030-4.

[8] Rodriguez-Lopez AM, Jackson DA, Iborra F, Cox LS. Asymmetry of DNA replication fork progression in Werner's syndrome. Aging Cell 2002; 1: 30-9.

[9] Rodriguez-Lopez AM, Whitby MC, Borer, CM, Bachler MA, Cox LS. Correction of proliferation and drug sensitivity defects in the progeroid Werner's Syndrome by Holliday junction resolution. Rejuvenation Res 2007; 10: 27-40.

[10] Sidorova JM, Li N, Folch A, Monnat RJ Jr. The RecQ helicase WRN is required for normal replication fork progression after DNA damage or replication fork arrest. Cell Cycle 2008; 7: 796807.

[11] Fry M, Loeb LA. Human werner syndrome DNA helicase unwinds tetrahelical structures of the fragile $\mathrm{X}$ syndrome repeat sequence d(CGG)n. J Biol Chem 1999; 274: 12797-802.
[12] Pirzio LM, Pichierri P, Bignami M, Franchitto A. Werner syndrome helicase activity is essential in maintaining fragile site stability. J Cell Biol 2008; 180: 305-14.

[13] Bohr VA. Deficient DNA repair in the human progeroid disorder, Werner syndrome. Mutat Res 2005; 577: 252-9.

[14] Campisi J, d'Adda di Fagagna F. Cellular senescence: when bad things happen to good cells. Nat Rev Mol Cell Biol 2007; 8: 72940 .

[15] Davis T, Baird DM, Haughton MF, Jones CJ, Kipling D. Prevention of accelerated cell aging in Werner syndrome using a p38 mitogen-activated protein kinase inhibitor. J Gerontol A Biol Sci Med Sci 2005; 60: 1386-93.

[16] Weir GC, Bonner-Weir S. Five stages of evolving beta-cell dysfunction during progression to diabetes. Diabetes 2004; 53(Suppl 3): S16-21.

[17] Butler AE, Janson J, Bonner-Weir S, Ritzel R, Rizza RA, Butler PC. Beta-cell deficit and increased beta-cell apoptosis in humans with type 2 diabetes. Diabetes 2003; 52: 102-10.

[18] Jonas JC, Sharma A, Hasenkamp W, et al. Chronic hyperglycemia triggers loss of pancreatic beta cell differentiation in an animal model of diabetes. J Biol Chem 1999; 274: 14112-21.

[19] Xu G, Stoffers DA, Habener JF, Bonner-Weir S. Exendin-4 stimulates both beta-cell replication and neogenesis, resulting in increased beta-cell mass and improved glucose tolerance in diabetic rats. Diabetes 1999; 48: 2270-6.

[20] Halvorsen TL, Beattie GM, Lopez AD, Hayek A, Levine F. Accelerated telomere shortening and senescence in human pancreatic islet cells stimulated to divide in vitro. J Endocrinol 2000; 166: 103 9.

[21] Masiello P. Animal models of type 2 diabetes with reduced pancreatic beta-cell mass. Int J Biochem Cell Biol 2006; 38: 873-93.

[22] Jay MA, Ren J, Peroxisome proliferator-activated receptor (PPAR) in metabolic syndrome and type 2 diabetes mellitus. Curr Diabetes Rev 2007; 3: 33-9.

[23] Gross B, Staels B. PPAR agonists: multimodal drugs for the treatment of type-2 diabetes. Best Pract Res Clin Endocrinol Metab 2007; 21: 687-710.

[24] Cheng AY, Leiter LA. PPAR-alpha: therapeutic role in diabetesrelated cardiovascular disease. Diabetes Obes Metab 2008; [Epub ahead of print].

[25] Honjo S, Yokote K, Fujishiro T, et al. Early amelioration of insulin resistance and reduction of interleukin-6 in Werner syndrome using pioglitazone. J Am Geriatr Soc 2008; 56: 173-4.

[26] Kuilman T, Michaloglou C, Vredeveld LC, et al. Oncogeneinduced senescence relayed by an interleukin-dependent inflammatory network. Cell 2008; 133: 1019-31.

[27] Acosta JC, O'Loghlen A, Banito A, et al. Chemokine signaling via the CXCR2 receptor reinforces senescence. Cell 2008; 133: 100618.

[28] Davis T, Kipling D. Werner Syndrome as an example of inflammaging: possible therapeutic opportunities for a progeroid syndrome? Rejuvenation Res 2006; 9: 402-7.

[29] Pagano G, Zatterale A, Degan P, et al. In vivo prooxidant state in Werner syndrome (WS): results from three WS patients and two WS heterozygotes. Free Radic Res 2005; 39: 529-33.

[30] Pagano G, Zatterale A, Degan P, et al. Multiple involvement of oxidative stress in werner syndrome phenotype. Biogerontology 2005; 6: 233-43.

[31] Saretzki G, Von Zglinicki T. Replicative aging, telomeres, and oxidative stress. Ann NY Acad Sci 2002; 959: 24-9.

[32] Tentolouris N, Nzietchueng R, Cattan V, et al. White blood cells telomere length is shorter in males with type 2 diabetes and microalbuminuria. Diabetes Care 2007; 30: 2909-15.

[33] Mettus RV, Rane SG. Characterization of the abnormal pancreatic development, reduced growth and infertility in $\mathrm{Cdk} 4$ mutant mice. Oncogene 2003; 22: 8413-21.

[34] Georgia S, Bhushan A. Beta cell replication is the primary mechanism for maintaining postnatal beta cell mass. J Clin Invest 2004; 114: $963-8$.

[35] Massip L, Garand C, Turaga RV, Deschenes F, Thorin E, Lebel M. Increased insulin, triglycerides, reactive oxygen species, and cardiac fibrosis in mice with a mutation in the helicase domain of the Werner syndrome gene homologue. Exp Gerontol 2005; 41: 157168 . 
[36] Moore G, Knoblaugh S, Gollahon K, Rabinovitch P, Ladiges W. Hyperinsulinemia and insulin resistance in Wrn null mice fed a diabetogenic diet. Mech Ageing Dev 2008; 129: 201-6.

[37] Hirai M, Suzuki S, Hinokio Y, et al. WRN gene 1367 Arg allele protects against development of type 2 diabetes mellitus. Diabetes Res Clin Pract 2005; 69: 287-92.

[38] Luo, Y, Ji, L, Han, X. The role of Werner's syndrome gene in the genetic susceptibility to the type 2 diabetes in Chinese population. Zhonghua Yi Xue Za Zhi 2000; 80: 360-1.

[39] Suh YH, Kim Y, Bang JH, et al. Analysis of gene expression profiles in insulin-sensitive tissues from pre-diabetic and diabetic Zucker diabetic fatty rats. J Mol Endocrinol 2005; 34: 299-315.

[40] Yokote K, Honjo S, Kobayashi K, et al. Metabolic improvement and abdominal fat redistribution in Werner syndrome by pioglitazone. J Am Geriatr Soc 2004; 52: 1582-3.
[41] Hattori S, Kasai M, Namatame T, Hattori Y, Kasai K. Pioglitazone treatment of insulin resistance in a patient with Werner's syndrome. Diabetes Care 2004; 27: 3021-2.

[42] Igarashi M, Wakasaki H, Takahara N, et al. Glucose or diabetes activates p38 mitogen-activated protein kinase via different pathways. J Clin Invest 1999; 103: 185-95.

[43] Kuma Y, Sabio G, Bain J, Shpiro N, Marquez R, Cuenda A. BIRB796 inhibits all p38 MAPK isoforms in vitro and in vivo. $\mathrm{J}$ Biol Chem 2005; 280: 19472-9.

[44] Branger J, van den Blink B, Weijer S, et al. Anti-inflammatory effects of a p38 mitogen-activated protein kinase inhibitor during human endotoxemia. J Immunol 2002; 168: 4070-7.

[45] Huang Q, Bu S, Yu Y, et al. Diazoxide prevents diabetes through inhibiting pancreatic beta-cells from apoptosis via $\mathrm{Bcl}-2 / \mathrm{Bax}$ rate and p38-beta mitogen-activated protein kinase. Endocrinology 2007; 148: 81-91.

(C) Lynne S. Cox; Licensee Bentham Open.

This is an open access article licensed under the terms of the Creative Commons Attribution Non-Commercial License (http://creativecommons.org/licenses/by-nc/3.0/) which permits unrestricted, non-commercial use, distribution and reproduction in any medium, provided the work is properly cited. 